\title{
Inflammatory Mediators in Tracheal Aspirates of Preterm Infants Participating in a Randomized Trial of Permissive Hypercapnia
}

\author{
Sarah Gentner ${ }^{1 *}$, Mandy Laube ${ }^{2}$, Ulrike Uhlig ${ }^{3}$, Yang Yang ${ }^{3}$, Hans W. Fuchs ${ }^{4}$, \\ Jens Dreyhaupt ${ }^{5}$, Helmut D. Hummler ${ }^{6}$, Stefan Uhlig ${ }^{3}$ and Ulrich H. Thome ${ }^{2}$ \\ ${ }^{1}$ Division of Vascular Surgery, University of Ulm, Ulm, Germany, ${ }^{2}$ Center for Pediatric Research Leipzig, Hospital for Children \\ and Adolescents, Division of Neonatology, University of Leipzig, Leipzig, Germany, ${ }^{3}$ Institute of Pharmacology and \\ Toxicology, RWTH Aachen University, Aachen, Germany, ${ }^{4}$ Center for Pediatrics, Medical Center - University of Freiburg, \\ Faculty of Medicine, University of Freiburg, Freiburg, Germany, ${ }^{5}$ Institute of Epidemiology and Medical Biometry, University \\ of UIm, Ulm, Germany, ${ }^{6}$ Division of Neonatology and Pediatric Critical Care, Department of Pediatrics, University of Ulm, \\ UIm, Germany
}

OPEN ACCESS

Edited by: Henry J. Rozycki, Virginia Commonwealth University, United States

Reviewed by:

Philip Lloyd Davies, NHS Greater Glasgow and Clyde,

United Kingdom

Gianluca Lista,

Ospedale dei Bambini

Vittore Buzzi, Italy

*Correspondence: Sarah Gentner sarah.gentner@uniklinik-ulm.de

Specialty section:
This article was submitted
to Neonatology,
a section of the journal
Frontiers in Pediatrics

Received: 04 September 2017 Accepted: 06 November 2017 Published: 21 November 2017

Citation:

Gentner S, Laube M, Uhlig U, Yang Y, Fuchs HW, Dreyhaupt J,

Hummler HD, Uhlig S and Thome UH (2017) Inflammatory Mediators in Tracheal Aspirates of Preterm Infants

Participating in a Randomized Trial of Permissive Hypercapnia.

Front. Pediatr. 5:246. doi: 10.3389/fped.2017.00246
Background: Ventilator-induced lung injury is considered to be a main factor in the pathogenesis of bronchopulmonary dysplasia (BPD). Optimizing ventilator strategies may reduce respiratory morbidities in preterm infants. Permissive hypercapnia has been suggested to attenuate lung injury. We aimed to determine if a higher $\mathrm{PCO}_{2}$ target range results in less lung injury compared to the control target range and possibly reduces pro-inflammatory cytokines and acid sphingomyelinase (ASM) in tracheal aspirates (TA), which has not been addressed before.

Methods: During a multicenter trial of permissive hypercapnia in extremely low birthweight infants (PHELBI), preterm infants (birthweight 400-1,000 g, gestational age 23 0/7-28 6/7 weeks) requiring mechanical ventilation within $24 \mathrm{~h}$ of birth were randomly assigned to a high $\mathrm{PCO}_{2}$ target or a control group. The high target group aimed at $\mathrm{PCO}_{2}$ values of $55-65,60-70$, and $65-75 \mathrm{mmHg}$ and the control group at $\mathrm{PCO}_{2}$ values of 40-50, 45-55 and 50-60 mmHg on postnatal days 1-3, 4-6, and 7-14, respectively. TA was analyzed for pro-inflammatory cytokines from postnatal day 2-21. BPD was determined at a postmenstrual age of 36 weeks \pm 2 days.

Main findings: Levels of inflammatory cytokines and ASM were similar in both groups: interleukin (IL)-6 ( $p=0.14), I L-8(p=0.43), I L-10(p=0.24), I L-1 \beta(p=0.11)$, macrophage inflammatory protein $1 \alpha(p=0.44)$, albumin $(p=0.41)$, neuropeptide $Y$ $(p=0.52)$, leukotriene $B_{4}(p=0.11)$, transforming growth factor- $\beta_{1}(p=0.68)$, nitrite $(p=0.15)$, and ASM $(p=0.94)$. Furthermore, most inflammatory mediators were strongly affected by the age of the infants and increased from postnatal day 2 to 21. BPD or death was observed in 14 out of 62 infants, who were distributed evenly between both groups.

Conclusion: The results suggest that high $\mathrm{PCO}_{2}$ target levels did not result in lower pulmonary inflammatory activity and thus reflect clinical results. This indicates that high $\mathrm{PCO}_{2}$ 
target ranges are not effective in reducing ventilator-induced lung injury in preterm infants, as compared to control targets.

Trial registration: ISRCTN56143743.

Keywords: permissive hypercapnia, bronchopulmonary dysplasia, pulmonary inflammation, tracheal aspirates, preterm infants

\section{INTRODUCTION}

Bronchopulmonary dysplasia (BPD), a form of chronic lung disease, is frequently observed in preterm infants. BPD development is associated with long-term oxygen supplementation $(1,2)$, and frequent re-admissions to hospitals $(3,4)$, resulting in high health-care costs (5). Lung damage and developmental arrest induced by BPD are mainly irreversible and the respiratory impairment may continue into adolescence and adulthood $(6,7)$.

Ventilator-induced baro/volutrauma represents one of the main factors in the pathogenesis of lung injury and subsequent BPD development and is mainly related to the magnitude of tidal volumes $(8,9)$. Permissive hypercapnia is a therapeutic strategy that attempts to minimize baro/volutrauma by reducing tidal volumes, which may result in alveolar hypoventilation with increased blood partial pressure of carbon dioxide $\left(\mathrm{PCO}_{2}\right)$. Possible benefits of permissive hypercapnia such as diminished lung injury and pulmonary inflammation (10) might be due to the reduction of lung stretch that occurs when tidal volumes are minimized. Some retrospective analyses suggested that higher arterial $\mathrm{PCO}_{2}$ values in the first days of life of preterm infants might be associated with a reduced incidence of $\operatorname{BPD}(11,12)$, whereas other studies did not $(13,14)$. Notably, several previous randomized trials of permissive hypercapnia did not demonstrate a reduction of BPD incidence (15-17), which might be due to small $\mathrm{PCO}_{2}$ differences between groups or limited sample sizes.

The preterm lung lacks antioxidant capacity and antiinflammatory mediators, leading to enhanced oxygen toxicity, inflammatory reactions, and repair processes (18-20). Thus, control of inflammatory processes is disturbed in immature lungs and inflammatory reactions may be prolonged and more damaging than in the mature lung. Cytokines can be measured in tracheal aspirates (TA) and reflect the extent of the inflammatory reactions $(21,22)$. Elevated levels of interleukin (IL)-1, IL-6, IL-8, intercellular adhesion molecule-1, macrophage inflammatory protein (MIP)- $1 \alpha$, transforming growth factor (TGF)- $\beta_{1}$, and leukotriene $B_{4}\left(\operatorname{LTB}_{4}\right)$ were detected within the first 10 days of life in the bronchoalveolar lavage fluid of preterm infants who subsequently developed BPD compared to infants who did not (23-29). In multicenter trials of high-frequency

\footnotetext{
Abbreviations: ASM, acid sphingomyelinase; BPD, bronchopulmonary dysplasia (chronic lung disease of prematurity); CPAP, continuous positive airway pressure; ELISA, enzyme-linked immunosorbent assay; IL-1, interleukin-1; IL-6, interleukin-6; IL-8, interleukin-8 (also called CXCL-8); IL-10, interleukin-10; IVH, intraventricular hemorrhage; $\mathrm{LTB}_{4}$, leukotriene $\mathrm{B}_{4}$; MIP- $1 \alpha$, macrophage inflammatory protein 1 alpha; NPY, neuropeptide $\mathrm{Y}$; $\mathrm{PCO}_{2}$, partial pressure of carbon dioxide; $\mathrm{PD}$, postnatal day; PHELBI, permissive hypercapnia in extremely low birth weight infants; TA, tracheal aspirate; TGF- $\beta_{1}$, transforming growth factor beta- 1 .
}

oscillatory ventilation (30) and inhaled nitric oxide (31), the clinical outcome was predicted by the IL- 8 and LTB $_{4}$ TA levels $(32,33)$. Furthermore, increased glycolipids, such as ceramide, were detected in the bronchoalveolar lavage fluid of patients with acute respiratory distress syndrome (34) and ceramide has been shown to induce apoptosis in lung epithelial cells $(35,36)$. More recently, ceramide and acid sphingomyelinase (ASM), the enzyme synthesizing ceramide, were shown to be involved in edema formation in models of acute lung injury $(37,38)$, and ASM levels were elevated in an ovine BPD model (39). Nitrite and nitrate are breakdown products of peroxynitrite, which may be formed in inflammatory processes from superoxide and nitric oxide. Furthermore, nitrotyrosine may be formed from peroxynitrite reacting with tyrosine residues $(40,41)$.

Thus, in addition to inflammatory cytokines, nitrite and nitrate as well as ASM might be involved in BPD development.

During a multicenter trial of permissive hypercapnia in extremely low birthweight infants (PHELBI) (42), two different target ranges of $\mathrm{PCO}_{2}$ were randomly allocated in order to determine whether a higher $\mathrm{PCO}_{2}$ target range prevents $\mathrm{BPD}$. Within this trial, TAs were collected at one study center to determine the effects of permissive hypercapnia on pulmonary inflammation. We hypothesized that permissive hypercapnia reduces pro-inflammatory cytokines and ASM in TA of preterm infants.

\section{MATERIALS AND METHODS}

\section{The PHELBI Trial}

In brief, infants with a birthweight of $400-1,000 \mathrm{~g}$ and a gestational age between $230 / 7$ and 28 6/7 weeks requiring endotracheal intubation and mechanical ventilation within $24 \mathrm{~h}$ of birth were enrolled. Infants were randomly allocated within $12 \mathrm{~h}$ of intubation to two different target ranges of $\mathrm{PCO}_{2}$. The high target group aimed at $\mathrm{PCO}_{2}$ values of $55-65 \mathrm{mmHg}$ on postnatal days (PD) $1-3$, followed by $60-70 \mathrm{mmHg}$ on PD $4-6$, and $65-75 \mathrm{mmHg}$ on $\mathrm{PD}$ 7-14. The control target group aimed at $\mathrm{PCO}_{2}$ values of $40-50 \mathrm{mmHg}$ on PD 1-3, followed by $45-55 \mathrm{mmHg}$ on PD 4-6, and 50-60 mmHg on PD 7-14 (42), representing a mild hypercapnia. Thereby, the intervention aimed at a difference of $15 \mathrm{mmHg}$ between the control and high target group for 14 days. Blood $\mathrm{PCO}_{2}$ was measured in 12-h intervals, or more frequently, if clinically indicated or when measurement results outside the target range occurred. To minimize volutrauma, a high ventilation rate $(60-80 / \mathrm{min})$ was favored over high tidal volumes in both groups. Initial ventilator settings comprised a rate of $60-80 / \mathrm{min}$ or greater, inspiratory time of $0.25-0.35 \mathrm{~s}$, positive end-expiratory pressure $3.6 \mathrm{mbar}$, and a peak inspiratory pressure (PIP) resulting in minimal to moderate chest rise. The rate was allowed to decrease 
only if the PIP was 14 mbar or lower. Synchronized ventilation or forms of volume control were applied at the discretion of the clinicians in charge of patient care (42). TAs were sampled from infants enrolled at the largest of the study centers (Ulm, Germany).

\section{Tracheal Aspirate Sampling}

Tracheal aspirates were sampled during normal medically indicated endotracheal suctioning procedures on PD 2, PD 4, PD 7 , PD 14, and PD 21, unless the infant was extubated earlier. If less than four specimens per day were obtained, further specimen were collected on the following day as available. No TA sampling was done within $4 \mathrm{~h}$ of a surfactant instillation. For sampling, a standardized procedure was conducted. A sterile mucus trap was inserted in the suctioning system, followed by endotracheal instillation of $0.5 \mathrm{ml} / \mathrm{kg}$ normal saline, and brief reconnection of the ventilator (3-5 breaths). Thereafter, suctioning was performed and TA collected. Afterward, the suctioning catheter was flushed with $0.5 \mathrm{ml}$ normal saline. TA were transferred to an appropriate tube and immediately centrifuged at $140 \times g$ and $4^{\circ} \mathrm{C}$ for $10 \mathrm{~min}$, whereupon, the supernatant was collected and immediately frozen. TA samples were held at $-80^{\circ} \mathrm{C}$ until ready for shipment to the laboratory, which was done on dry ice. The number of infants from whom TA were collected declined with advancing postnatal age. Main factors for the declining number of samples were extubations within the first 21 days of life, reduced number of clinically indicated tracheal suctioning procedures due to improved pulmonary function, transfer to other hospitals, and death. All procedures of this study were approved by the institutional review board of the University of Ulm and informed parental permission was obtained.

\section{Tracheal Aspirate Analyses}

Tracheal aspirate analyses were performed at the Institute of Pharmacology and Toxicology of the Technical University, Aachen, Germany. To determine the TA levels of IL-6, IL-8, IL-1 $\beta$, IL-10, and MIP-1 $\alpha$, a Bio-Plex Cytokine assay (Bio-Rad Laboratories, Munich, Germany) was used (43). Enzyme-linked immunosorbent assays were conducted to analyze the TA concentrations of TGF- $\beta_{1}$ (R\&D Systems GmbH, WiesbadenNordenstadt, Germany), albumin (AssayPro, St. Charles, IL, USA), and nitrotyrosine (Cell Sciences, Canton, OH, USA). In addition, competitive binding assays were used for neuropeptide Y (NPY) (Phoenix Europe GmbH, Karlsruhe, Germany) and $\mathrm{LTB}_{4}$ (R\&D Systems GmbH). Nitrite TA levels were determined by a Griess reaction assay ( $\mathrm{R} \& \mathrm{D}$ Systems $\mathrm{GmbH})$. All assays were performed according to the manufacturer's recommendations. For ASM, a proprietary assay was used as described before (44). To increase the sample amount and decrease variations of dilution, specimen from the same patient and day were pooled. To date, no uniformly accepted standard is available and thus no attempt to normalize TA levels was made. As recommended by the European Respiratory Task Force on Bronchoalveolar Lavage in children $(45,46)$, we expressed the data per milliliter of TA.

\section{Clinical Outcome}

The primary outcome of the trial was death or BPD before 36 weeks postmenstrual age according to the physiological definition of BPD-i.e., requiring mechanical pressure support or supplemental oxygen at 36 weeks postmenstrual age within \pm 2 days, including an oxygen reduction test for infants requiring less than $0.3 \mathrm{FiO}_{2}$ (BPD or death) $(42,47)$.

\section{Statistical Analyses}

Demographic and clinical outcome data were compared between the high target and the control target group by Mann-Whitney $U$-test or Fisher's exact test as appropriate. TA concentrations were compared by mixed model two-way (factors being time and target group) analyses of variance (ANOVA) with a heterogeneous unstructured covariance structure SAS software 9.4 (MIXED procedure, SAS, Cary, NC, USA). In the figures, the effect of postnatal age (time) is denoted below the $x$-axis and the target group effects on each single day at the respective time points.

\section{RESULTS}

During the enrollment period from 2008 to 2012, TAs were collected from 62 infants being allocated equally to the high $\mathrm{PCO}_{2}$ target and the control target group. Demographic data were similar between both groups with respect to the number of patients, gestational age, gender, birthweight, prenatal steroids, and infant age at intubation (Table $\mathbf{1}$ ).

Mixed model ANOVA of target group and postnatal age yielded the $p$-values shown in Table 2 . Furthermore, the influence of $\mathrm{PCO}_{2}$ was determined for each measured time point separately from PD 2 to PD 21. Nitrotyrosine TA levels were below the limit of detection (data not shown). Nitrite TA levels were similar between infants assigned to the high target and

TABLE 1 | Demographic and outcome characteristics of the infants.

\begin{tabular}{|c|c|c|c|}
\hline & $\begin{array}{l}\text { Control } \\
\text { target group }\end{array}$ & $\begin{array}{l}\text { High } \\
\text { target group }\end{array}$ & $p$-Value \\
\hline Number of patients & 31 & 31 & \\
\hline Gestational age (days) ${ }^{\mathrm{a}}$ & $178(61-199)$ & 179 (163-201) & 0.32 \\
\hline Birth weight $(\mathrm{g})^{\mathrm{a}}$ & $690(415-970)$ & 730 (440-990) & 0.62 \\
\hline Male & $14(45 \%)$ & 17 (55\%) & 0.61 \\
\hline Prenatal steroids & $26(84 \%)$ & 29 (94\%) & 0.43 \\
\hline Apgar score 5-min ${ }^{a}$ & $8.0(5.0-10.0)$ & $8.5(3.0-10.0)$ & 0.11 \\
\hline Apgar score 10-mina & $9.0(6.0-10.0)$ & $9.5(5.0-10.0)$ & 0.18 \\
\hline Age at intubation (h) & $2(0-21)$ & $0(0-17)$ & 0.54 \\
\hline $\begin{array}{l}\text { Bronchopulmonary } \\
\text { dysplasia }^{b}\end{array}$ & $5(17 \%)$ & $7(23 \%)$ & 0.75 \\
\hline Death & $1(3 \%)$ & $0(0 \%)$ & 1.00 \\
\hline $\begin{array}{l}\text { Intraventricular hemorrhage } \\
\text { (all grades) }^{\mathrm{b}}\end{array}$ & $12(40 \%)$ & 12 (39\%) & 1.00 \\
\hline $\begin{array}{l}\text { Extubated at } 36 \text { weeks/ } \\
\text { month }^{b}\end{array}$ & 30 (100\%) & 31 (100\%) & 1.00 \\
\hline Age at extubation (days) ${ }^{a}$ & $25.5(3-74)$ & $20(2-77)$ & 0.42 \\
\hline $\begin{array}{l}\text { No continuous positive } \\
\text { airway pressure (CPAP) } \\
36 \text { weeks/month }^{b}\end{array}$ & 27 (90\%) & 26 (84\%) & 0.71 \\
\hline $\begin{array}{l}\text { Age at CPAP } \\
\text { termination (days) }\end{array}$ & $57(7-79)$ & $47(7-73)$ & 0.15 \\
\hline Mechanical ventilation (h) & $1,252.5(152-2,045)$ & $1,130(42-2,059)$ & 0.23 \\
\hline $\mathrm{No} \mathrm{O}_{2} 36$ weeks/month ${ }^{\mathrm{b}}$ & $25(83 \%)$ & $25(81 \%)$ & 1.00 \\
\hline
\end{tabular}

a Median (minimum-maximum), Mann-Whitney U-test; all others: Fisher's exact test. ${ }^{b} n$ (\% of surviving infants). 
TABLE 2 | Mixed model analyses of variance ( $p$-values).

\begin{tabular}{lcc}
\hline & Target group & Postnatal age \\
\hline Nitrite & $p=0.1504$ & $p<0.0001$ \\
Interleukin (IL)-6 & $p=0.1436$ & $p=0.0382$ \\
IL-1 $\beta$ & $p=0.1075$ & $p<0.0001$ \\
Transforming growth factor- $\beta_{1}$ & $p=0.6798$ & $p=0.0007$ \\
IL-10 & $p=0.2414$ & $p=0.0788$ \\
IL-8 & $p=0.4268$ & $p=0.1318$ \\
Macrophage inflammatory protein-1 $1 \alpha$ & $p=0.4445$ & $p=0.0008$ \\
Leukotriene $B_{4}$ & $p=0.1067$ & $p=0.0036$ \\
Neuropeptide $Y$ & $p=0.5218$ & $p=0.0486$ \\
Acid sphingomyelinase & $p=0.9408$ & $p=0.0011$ \\
Albumin & $p=0.4095$ & $p=0.8114$
\end{tabular}

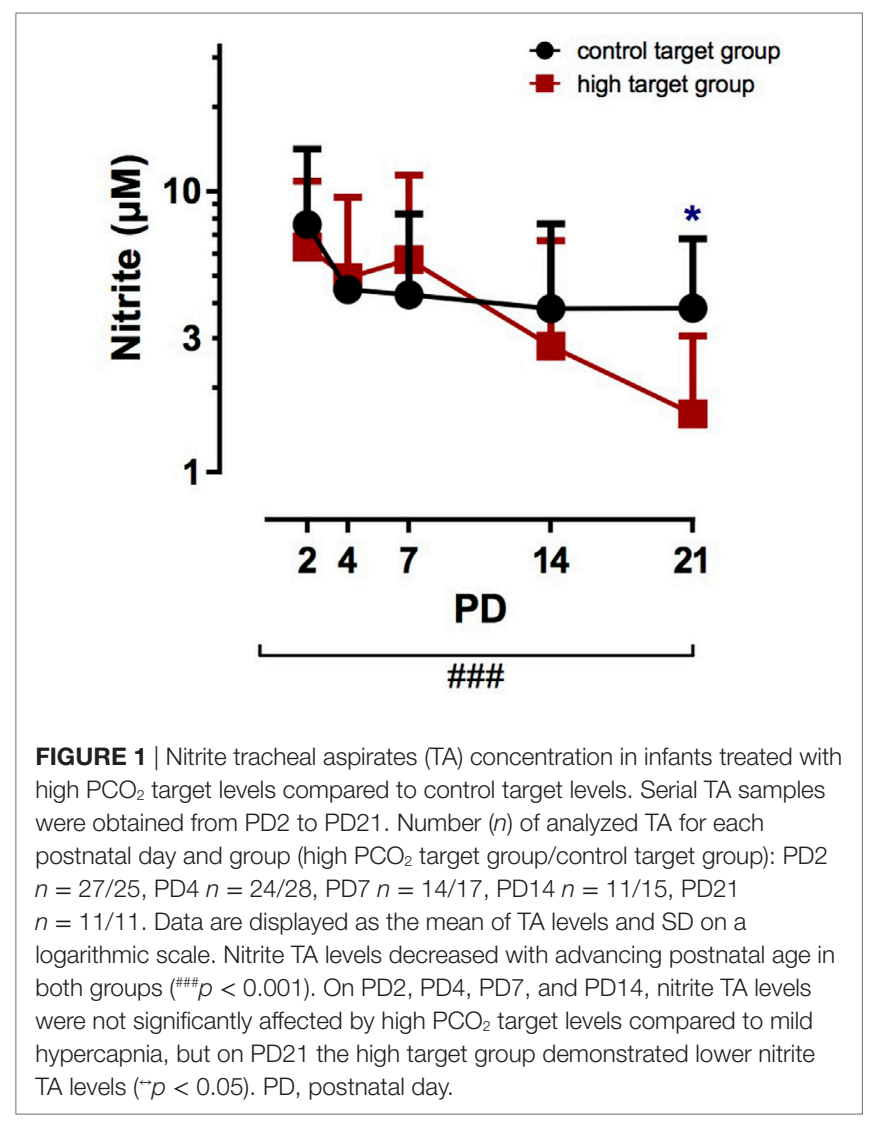

control target groups from PD 2 to PD 14 (Figure 1). On PD 21, the high target group showed significantly lower nitrite TA levels with $1.61 \pm 1.45 \mu \mathrm{M}$ (mean $\pm \mathrm{SD})$ compared to $3.84 \pm 2.95 \mu \mathrm{M}$ in the control group $(p<0.05)$. Furthermore, nitrite TA levels markedly decreased in both groups over the study period from PD 2 to PD $21(p<0.001)$.

Postnatal age also affected IL- 6 TA concentration since levels of both, the high target group and the control target group, significantly increased over the study period from PD 2 to PD 21 (Figure 2A; $p<0.05$ ). The different $\mathrm{PCO}_{2}$ target levels, however, did not affect IL-6 TA levels from PD 2 to PD 21. Similarly, IL-1 $\beta$ TA levels were not affected by the $\mathrm{PCO}_{2}$ target group (Figure 2B), but postnatal age strongly increased IL-1 $\beta$ TA levels in both groups from PD 2 to PD $21(p<0.001)$. Furthermore, TGF- $\beta_{1}$ TA levels increased with advancing postnatal age (Figure $2 \mathrm{C}$; $p<0.001$ ), but no difference in TGF- $\beta_{1}$ TA levels was observed between the high target group and the control target group. IL-10 TA levels were neither affected by the $\mathrm{PCO}_{2}$ target group nor postnatal age, as no significant differences were detected during the study period (Figure 2D). In addition, different $\mathrm{PCO}_{2}$ target levels did not affect NPY TA levels, while postnatal age decreased NPY TA levels over the study period from PD 2 to PD 21 (Table 2; $p<0.05)$.

No differences in IL-8 TA levels between the target groups were observed on PD 2 to PD 7 (Figure 3A), but on PD 14, the high target group showed significantly lower IL-8 TA levels with $1.499 \pm 1.792 \mathrm{pg} / \mathrm{ml}$ compared to $8.480 \pm 11.107 \mathrm{pg} / \mathrm{ml}$ in the control target group $(p<0.05)$. However, the subsequent measurement on PD 21 showed no differences of IL-8 TA levels between both target groups. In addition, postnatal age did not affect IL-8 TA levels. In contrast to IL-8, postnatal age strongly affected MIP-1 $\alpha$ TA levels, which significantly increased from PD 2 to PD 21 in both target groups (Figure 3B; $p<0.001$ ). The $\mathrm{PCO}_{2}$ target group did not significantly alter MIP-1 $\alpha$ TA levels, as no difference was observed between the groups. Similarly, $\mathrm{LTB}_{4} \mathrm{TA}$ levels were not affected by $\mathrm{PCO}_{2}$ target levels from $\mathrm{PD} 2$ to $\mathrm{PD} 21$ (Figure 3C). However, postnatal age strongly increased $\mathrm{LTB}_{4} \mathrm{TA}$ levels in both groups $(p<0.01)$.

Finally, the $\mathrm{PCO}_{2}$ target levels did not alter the ASM TA levels, as no significant difference was observed between the high target group and the control target group from PD2 to PD21 (Figure 4A), while postnatal age significantly increased ASM TA levels in both target groups $(p<0.05)$. Albumin TA levels were not affected by postnatal age or the target group from PD 2 to PD

\section{1 (Figure 4B).}

Day-by-day mean values of $\mathrm{PCO}_{2}$ (high $\mathrm{PCO}_{2}$ target group: $54.07 \pm 8.36 \mathrm{mmHg}$ and control target group $48.94 \pm 7.05 \mathrm{mmHg}$ ) and $\mathrm{pH}$ (high $\mathrm{PCO}_{2}$ target group: $7.23 \pm 0.06$ and control target group $7.25 \pm 0.04$ ) differed significantly between study groups, as intended in the study protocol (Figures $\mathbf{5}$ and $\mathbf{6}$ ). In summary, no pronounced differences in TA mediator levels of preterm infants between the high $\mathrm{PCO}_{2}$ target group and the control target group from PD 2 to PD 21 were observed.

Daily mean values for the PIP were significantly lower in patients randomized to the high target group as compared to the control target group (linear mixed effects regression model, $p=0.01$ ), suggesting increased weaning efforts in the high target group (Figure 7).

\section{DISCUSSION}

In contrast to our initial hypothesis, high $\mathrm{PCO}_{2}$ target levels did not result in lower inflammatory activity concerning the analyzed factors IL-6, IL- $1 \beta, \mathrm{LTB}_{4}$, TGF- $\beta_{1}$, NPY, MIP- $1 \alpha$, albumin, and ASM. Nitrite TA levels were reduced in the high target group on $\mathrm{PD} 21$. Since $\mathrm{PCO}_{2}$ targets were discontinued on PD 14 according to the study protocol, a difference observed only on PD 21 is not convincing. The anti-inflammatory mediator IL-10 was also not affected by high $\mathrm{PCO}_{2}$ target levels. Only IL- 8 showed a 


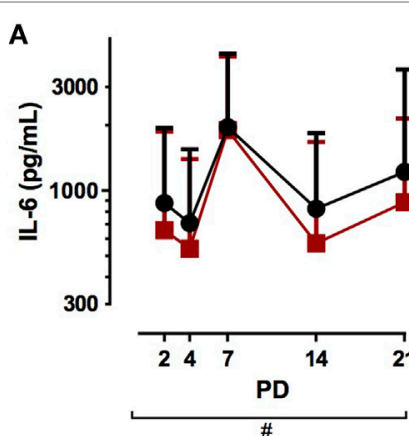

C

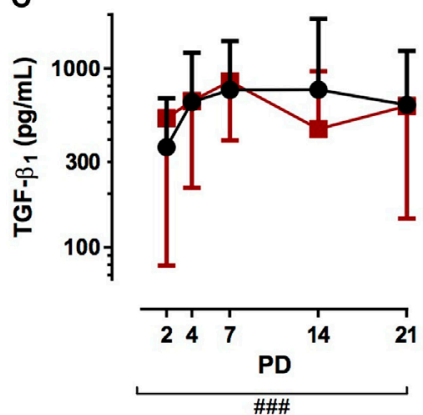

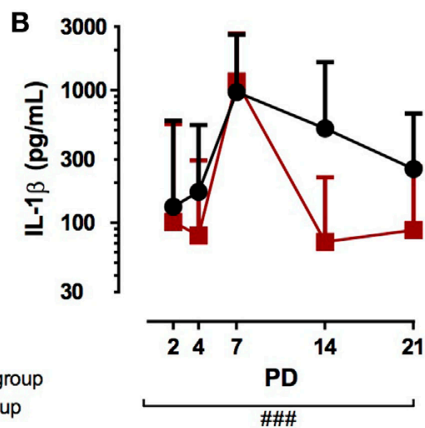

D

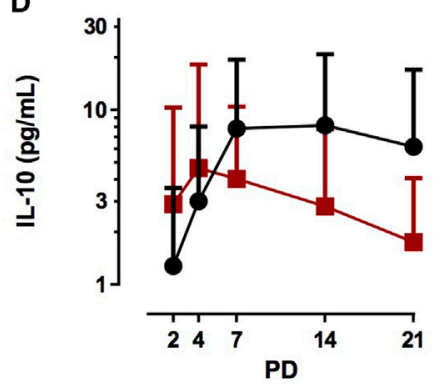

FIGURE 2 | Cytokine tracheal aspirates (TA) concentrations in infants treated with high $\mathrm{PCO}_{2}$ target levels compared to control target levels. Serial TA samples were obtained from PD2 to PD21. Data are displayed as the mean of TA levels and SD on a logarithmic scale. (A) Interleukin (IL)-6: number ( $n$ ) of analyzed TA for each postnatal day and group (high $\mathrm{PCO}_{2}$ target group/control target group): PD2 $n=27 / 25$, PD4 $n=24 / 28, \mathrm{PD} 7 n=17 / 17$, PD14 $n=11 / 15$, PD21 $n=11 / 11$. IL-6 TA levels were not affected in the high $\mathrm{PCO}_{2}$ target group from PD2 to PD21, but increased with advancing postnatal age in both groups ( $\left.{ }^{\prime} p<0.05\right)$. (B) IL-1 $\beta$ : number (n) of analyzed TA for each postnatal day and group (high $\mathrm{PCO}_{2}$ target group/control target group): PD2 $n=27 / 25$, PD4 $n=24 / 28, \mathrm{PD} 7 n=17 / 17$, PD14 $n=11 / 15$, PD21 $n=11 / 11$. IL-1 $\beta$ TA levels strongly increased with advancing postnatal age in both groups (\#\#\# $p<0.001)$. High PCO ${ }_{2}$ target levels did not affect IL-1 $\beta$ TA levels from PD2 to PD21. (C) Transforming growth factor (TGF)- $\beta_{1}$ : number $(n)$ of analyzed TA for each postnatal day and group (high PCO ${ }_{2}$ target group/ control target group): PD2 $n=26 / 25$, PD4 $n=23 / 27$, PD7 $n=15 / 17$, PD14 $n=11 / 15$, PD21 $n=11 / 11$. TGF- $\beta_{1}$ TA levels were not altered by the treatment group from PD2 to PD21, but demonstrated elevated TA levels with advancing postnatal age in both groups (\#\#\#<0.001). (D) IL-10: number ( $n$ ) of analyzed TA for each postnatal day and group (high $\mathrm{PCO}_{2}$ target group/control target group): PD2 $n=27 / 25, \mathrm{PD} 4 n=24 / 28, \mathrm{PD} 7 n=17 / 17, \mathrm{PD} 14 n=11 / 15, \mathrm{PD} 21 n=11 / 11$. IL-10 TA levels were not affected by the target group or postnatal age. PD, postnatal day.

significantly reduced TA level on PD 14 in the high target group, which did not persist until the next measured time point, PD 21.

Overall, the data demonstrate that inflammatory mediators in TA of preterm infants are not affected by different $\mathrm{PCO}_{2}$ targets as used in this trial, which has not been addressed before. These results are consistent with the results of the PHELBI multicenter trial showing neither a reduction of BPD incidence nor BPD severity in the high target group and may thus help to explain the clinical results of the PHELBI trial (42). Since inflammatory processes are a main factor in the pathogenesis of BPD (21), we assume that the comparable levels of inflammatory mediators observed in our study indicate that inflammatory processes were of similar strength in both study groups leading to an equal incidence and severity of BPD.

Inflammatory mediators are thought to have various effects on lung tissue and contribute to lung pathology. Elevated TA cytokine levels indicate pathologic immune responses leading to inflammatory processes in the lung. Different studies suggest that IL- $1 \beta$, IL-6, IL- 8, MIP- $1 \alpha, \mathrm{LTB}_{4}$, and TGF- $\beta_{1}$ levels are associated with subsequent BPD development and promote lung fibrosis $(24,27-29,48-52)$. Notably, TGF- $\beta_{1}$ was demonstrated to inhibit alveolar fluid clearance by downregulating $\beta_{2}$-adrenergic receptors $(52,53)$. In addition, pro-fibrotic TGF- $\beta_{1}$ stimulates collagen synthesis and epithelial-mesenchymal transition, contributing to interstitial thickening in vivo (54). In contrast to our results, mouse pups exposed to chronic hypercapnia exhibit an altered lung matrix composition with decreased collagen levels (55), suggesting beneficial anti-fibrotic effects of high $\mathrm{PCO}_{2}$ levels. However, we did not observe an effect of high $\mathrm{PCO}_{2}$ levels on TGF$\beta_{1}$ TA concentrations in preterm infants. Furthermore, IL- 8 and $\operatorname{LTB}_{4}(24,56)$, as well as IL- 6 and NPY $(23,29,57,58)$ contribute to lung edema by increasing microvascular permeability in vitro. Elevated microvascular permeability is commonly associated with increased albumin concentrations in TA (24). We neither observed effects on $\mathrm{LTB}_{4}$, IL-6, and NPY induced by moderate permissive hypercapnia nor on albumin concentrations, suggesting no difference in microvascular permeability between the study groups. In contrast to our results, hypercapnia reduced IL-6 and IL- $1 \beta$ expression in murine lung tissue of a paraquat-induced acute lung injury model accompanied by decreased numbers of neutrophils in lung tissue and inflammatory infiltration in alveolar septa compared to normoxia (59). However, results of this study were obtained after $1 \mathrm{~h}$ of mechanical ventilation and preclude assessment of long-term effects. Although reduced TA levels of 


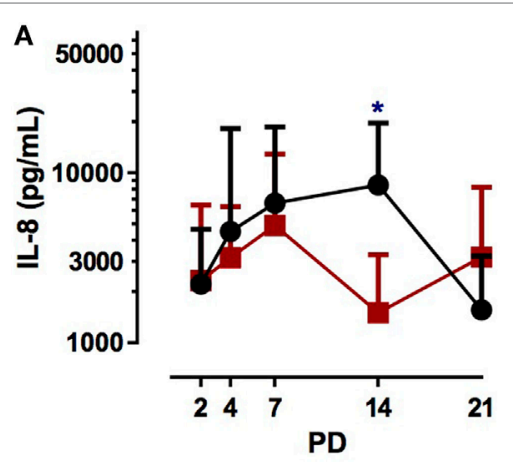

C

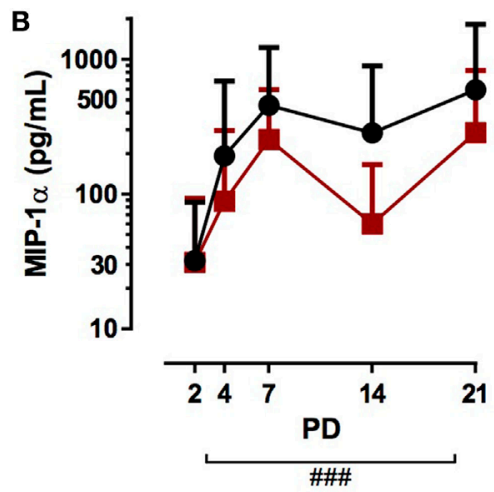

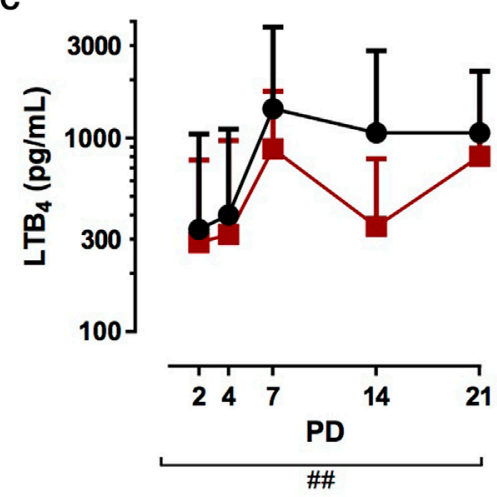

control target group

high target group

FIGURE 3 | Chemokine tracheal aspirates (TA) concentrations in infants treated with high $\mathrm{PCO}_{2}$ target levels compared to control target levels. Serial TA samples were obtained from PD2 to PD21. Data are displayed as the mean of TA levels and SD on a logarithmic scale. (A) Interleukin (IL)-8: number (n) of analyzed TA for each postnatal day and group (high $\mathrm{PCO}_{2}$ target group/control target group): $\mathrm{PD} 2 n=25 / 25, \mathrm{PD} 4 n=28 / 28, \mathrm{PD} 7 n=17 / 17, \mathrm{PD} 14 n=15 / 15, \mathrm{PD} 21 n=11 / 11$. IL-8 TA levels were not affected in the high $\mathrm{PCO}_{2}$ target group from PD2 to PD7, but on PD14, high $\mathrm{PCO}_{2}$ target levels significantly decreased IL-8 TA levels $(\leftrightarrow p<0.05)$. On PD21, no difference was observed between the target groups and postnatal age did not affect IL-8 TA levels. (B) Macrophage inflammatory protein (MIP)-1 $\alpha$ : number $(n)$ of analyzed TA for each postnatal day and group (high $\mathrm{PCO}_{2}$ target group/control target group): PD2 $n=27 / 25, \mathrm{PD} 4 n=24 / 28, \mathrm{PD} 7$ $n=17 / 17$, PD14 $n=11 / 15$, PD21 $n=11 / 11$. MIP-1 $\alpha$ TA levels were not altered by the treatment from PD2 to PD21, but demonstrated elevated TA levels with advancing postnatal age in both groups (\#\# $p<0.001)$. (C) Leukotriene $\mathrm{B}_{4}\left(\mathrm{LTB}_{4}\right)$ TA levels were not affected by the target group, but demonstrated elevated TA levels with advancing postnatal age in both groups $(\# p<0.01)$. PD, postnatal day.
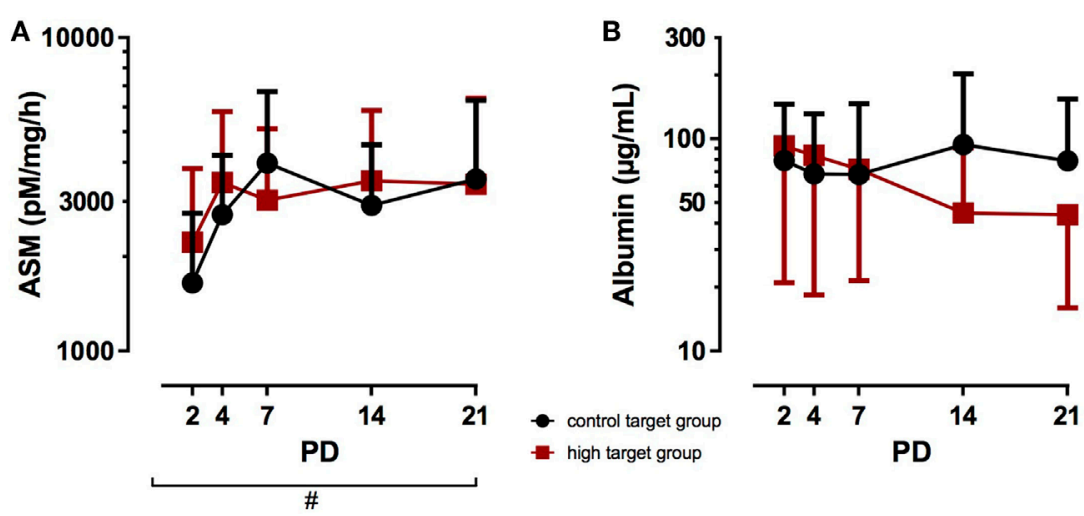

FIGURE 4 | Acid sphingomyelinase (ASM) and albumin tracheal aspirates (TA) concentrations in infants treated with high $\mathrm{PCO}_{2}$ target levels compared to control target levels. Serial TA samples were obtained from PD2 to PD21. Data are displayed as the mean of TA levels and SD on a logarithmic scale. (A) ASM: number (n) of analyzed TA for each postnatal day and group (high $\mathrm{PCO}_{2}$ target group/control target group): PD2 $n=27 / 25, \mathrm{PD} 4 n=24 / 28, \mathrm{PD} 7 n=17 / 17, \mathrm{PD} 14$ $n=11 / 15$, PD21 $n=11 / 11$. ASM TA levels were not affected in the high $\mathrm{PCO}_{2}$ target group from PD2 to PD21, but increased with advancing postnatal age in both groups ( $\# p<0.05)$. (B) Albumin: number $(n)$ of analyzed TA for each postnatal day and group (high $\mathrm{PCO}_{2}$ target group/control target group): PD2 $n=27 / 25$, PD4 $n=24 / 28$, PD7 $n=17 / 17$, PD14 $n=11 / 15$, PD21 $n=11 / 11$. Albumin TA levels were not affected by the target group or postnatal age. PD, postnatal day. 
$\mathrm{PCO}_{2}$ while intubated

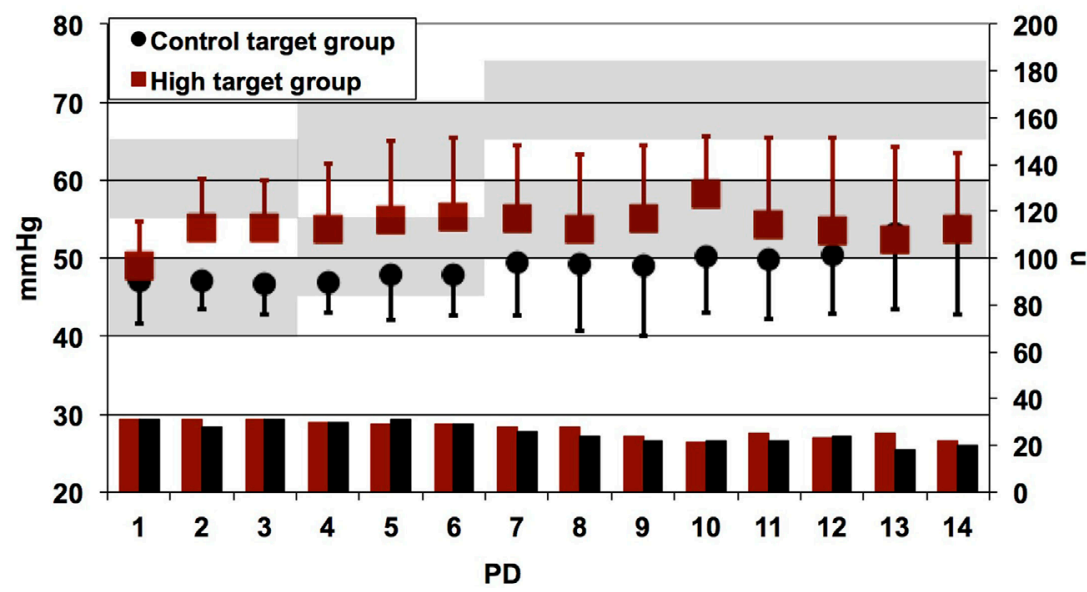

FIGURE 5 | Daily mean values of the partial pressure of carbon dioxide $\left(\mathrm{PCO}_{2}\right)$ in all patients who were intubated at the time of measurement. Error bars indicate SDs; lower bars indicate numbers of patients contributing data. Shaded areas indicate the target ranges of the high target and control target groups. The $\mathrm{PCO}_{2}$ values were significantly higher in patients randomized to the high target group as compared to the control target group (linear mixed effects regression model, $p<0.0001$ ), although the high target range was frequently not achieved owing to the patients' own respiratory efforts. The main reason for absent data was extubation. PD, postnatal day.

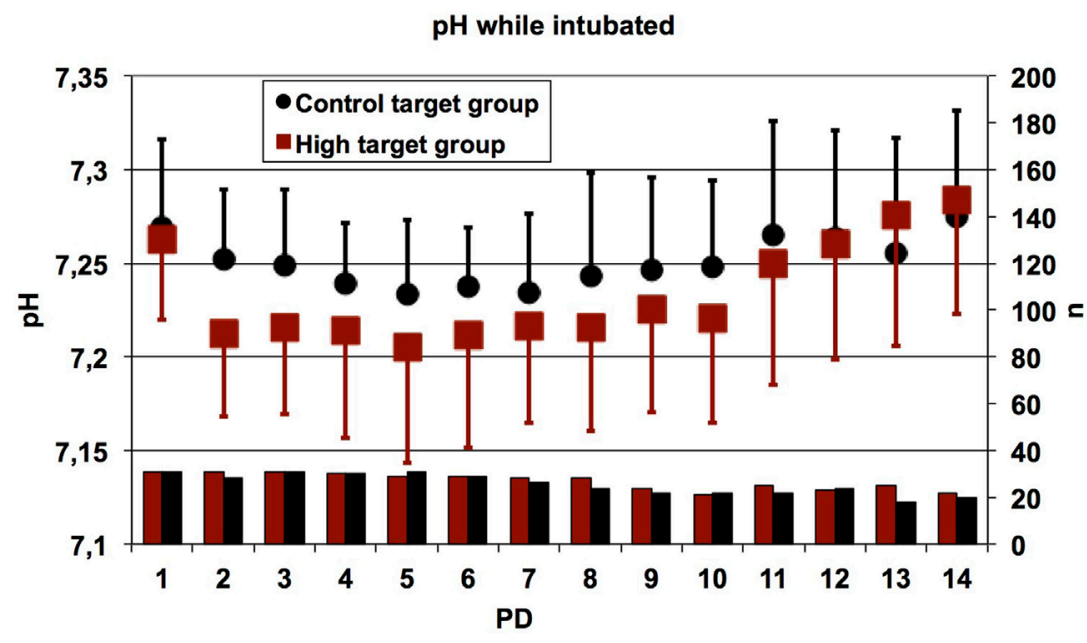

FIGURE 6 | Daily mean values of the $\mathrm{pH}$ in all patients who were intubated at the time of measurement. Error bars indicate SDs; lower bars indicate numbers of patients contributing data. The $\mathrm{pH}$ values were significantly lower in patients randomized to the high target group as compared to the control target group (linear mixed effects regression model, $p<0.0001)$. The main reason for absent data was extubation. PD, postnatal day.

IL-8 were detected in the high $\mathrm{PCO}_{2}$ target group on PD 14, the reduction of IL-8 levels did not persist until PD 21, questioning the physiological relevance of the observed effect. Another parameter contributing to lung edema is platelet-activating factor (PAF), which acts by activating the cyclooxygenase pathway and ASM. More recently, ceramide and ASM, the enzyme synthesizing ceramide, were shown to be involved in lung edema formation induced by PAF $(37,44)$. Furthermore, ceramide was shown to induce apoptosis in lung epithelial cells $(35,36)$. There has not yet been a study testing the association between ASM levels and the development of BPD. Taken together, levels of inflammatory and fibrotic mediators were similar in both study groups.

Although we speculated that high $\mathrm{PCO}_{2}$ target levels might reduce mechanical stress, $\mathrm{PCO}_{2}$ target levels did not seem to influence pulmonary inflammatory activity. This might be due to altered $\mathrm{pH}$ values, which possibly affects a large number of enzymes that are out of their $\mathrm{pH}$ optimum, thus counteracting any benefits. In contrast to our results, adult patients suffering from acute respiratory distress syndrome demonstrated beneficial reductions of pulmonary inflammatory cytokines 


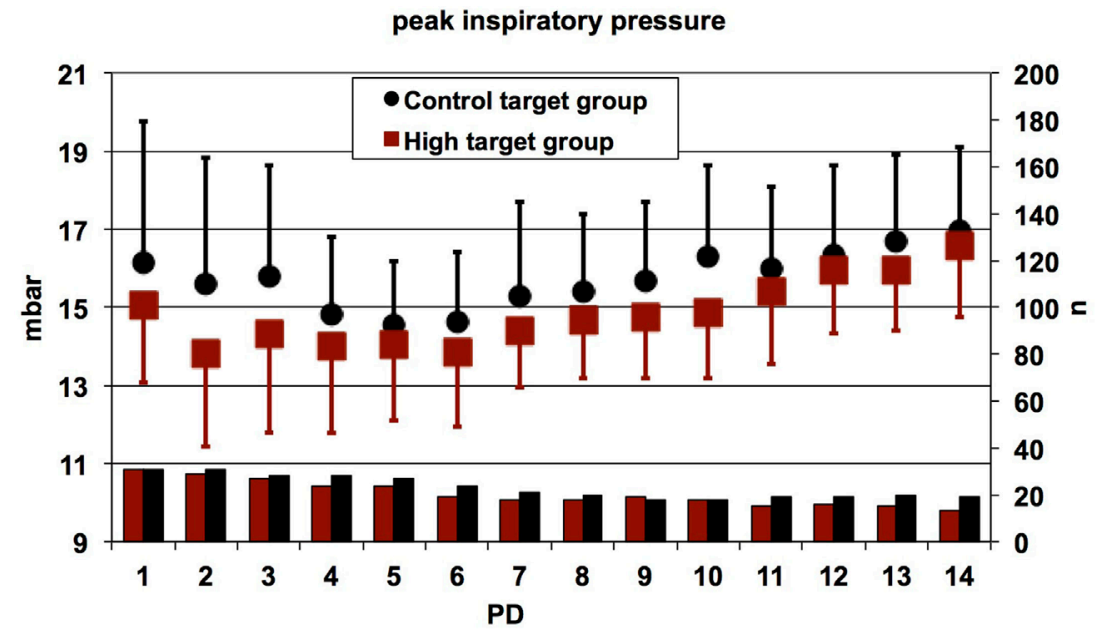

FIGURE 7 | Daily mean values for the peak inspiratory pressure (PIP) in conventionally ventilated patients. Error bars indicate SDs; lower bars indicate numbers of patients contributing data. The PIP values were significantly lower in patients randomized to the high target group as compared to the control target group (linear mixed effects regression model, $p=0.01$ ). The main reason for absent data was the use of high-frequency oscillatory ventilation or proportional assist ventilation or extubation. PD, postnatal day.

and neutrophils, which was achieved by lowering the intensity of mechanical ventilation and thus tolerating higher $\mathrm{PCO}_{2}(60)$. The reason for the difference of effects of high $\mathrm{PCO}_{2}$ target levels between adults and preterm infants remains to be determined.

Hypercapnia in adult and newborn rodent models demonstrated attenuation of lung neutrophil recruitment, pulmonary cytokine concentrations, cell apoptosis, and oxygen-derived and nitrogen-derived free radical injury (61). Neonatal rats exposed to $60 \%$ oxygen for 14 days showed phagocyte influx, interstitial thickening, and impaired alveolar formation, which was attenuated by concurrent hypercapnia $\left(5.5 \% \mathrm{CO}_{2}\right)(62)$. Thus, inhaled $5.5 \% \mathrm{CO}_{2}$ provided partial protection against parenchymal and vascular injury in a mouse model of chronic neonatal lung injury, although the authors acknowledge possible critical differences between permissive and therapeutic hypercapnia in their effects on the lung (62). More recent studies suggested that hypercapnia might also have undesirable effects on lung tissues (63-66). Hypercapnic acidosis impairs pulmonary epithelial wound healing (67), which is NF- $\mathrm{kB}$ dependent and involves inhibition of cellular migration. Thus, hypercapnic acidosis might attenuate injury pathways, but on the other hand, it possibly interferes with lung repair (68). Moreover, lung fluid clearance is impaired by hypercapnia independently of $\mathrm{pH}$ by triggering endocytosis and thus inhibition of Na,K-ATPase activity in alveolar epithelial cells (69). Another study demonstrated an association between higher $\mathrm{PCO}_{2}$ levels during the first few days of life and the subsequent incidence of BPD (13), further questioning the potential clinical benefit of hypercapnia in preterm infants.

Postnatal age of the infants affected almost every analyzed factor demonstrated by significant changes of TA nitrite, IL-6, IL1 $\beta$, TGF- $\beta_{1}$, MIP- $1 \alpha$, NPY, LTB ${ }_{4}$, and ASM levels. The inflammatory mediators IL-6, IL1 $\beta$, TGF- $\beta_{1}$, MIP- $1 \alpha, \mathrm{LTB}_{4}$, and ASM increased with advancing postnatal age, while nitrite and NPY levels declined during the study period.
Small differences in TA cytokine levels may be missed in our study because of the small sample size. However, we limited the collection of TA to the largest center of all participating centers of the PHELBI trial to counteract inter-center variations such as differences of tracheal suctioning procedures and clinical care. Therefore, even a multicenter TA sampling study may not yield more precise results and more statistically significant differences. Furthermore, if there are clinically important differences in a larger sample size, unequivocal trends should already be observed in analyses of inflammatory mediators alike. Thus, we assume that pulmonary inflammatory activity was indeed similar in both study groups and important differences would not have become detectable with a larger sample size. Moreover, the biochemical results go along with the clinical outcome in this study, which indicates that high target levels were as beneficial as control target levels in terms of ventilator-induced lung injury, lung inflammation, and the development of chronic lung disease (42). In addition, our results agree with the clinical results of other randomized controlled studies, which also did not observe a reduced incidence of $B P D$ associated with permissive hypercapnia in preterm infants $(16,32,70)$.

According to the definition, 12 of 62 infants suffered from BPD in our study, which were distributed statistical comparably in both treatment groups. Thus, similar cytokine levels in both groups were followed by a similar clinical outcome in the patients studied here as well as in the main multicenter trial (42), which might be viewed as a prediction of the main trial outcome by the observed cytokine levels. Differences in the rate of BPD in comparison to previous studies $(24,25,28,71)$ might be explained by different BPD definitions and the multitude of improvements that have been introduced into neonatal care.

A limitation of this study is the declining number of infants supplying TA with advancing postnatal age, because infants are extubated as soon as clinically possible to limit potential lung 
damage from mechanical ventilation. Therefore, infants, who were more prone to develop BPD, remained longer in the study and supply more TA due to continuing invasive mechanical ventilation. Thus, after 14 or 21 days of life, the acquired TA may not be completely representative for the whole group, since TA was only available from infants who still received invasive mechanical ventilation at that time. Furthermore, normalization of TA to correct for dilution is still controversial. Different techniques have been proposed, including albumin content, urea, or secretory immunoglobulin A concentrations. However, no uniformly accepted correction factor is currently available. We did not correct our results for dilution and expressed the data per milliliter of TA, as recommended by the European Respiratory Task Force on Bronchoalveolar Lavage in children $(45,46)$.

\section{CONCLUSION}

No differences in the levels of most cytokines were found when comparing infants with control or high $\mathrm{PCO}_{2}$ targets. In addition, there were no differences in the clinical outcome, which was in accordance with the results of the main multicenter PHELBI trial. We assume that higher $\mathrm{PCO}_{2}$ target ranges are as beneficial as the control target range. Indeed, high target levels may reduce mechanical stress for the pulmonary parenchyma, but possible suboptimal $\mathrm{pH}$-values might impede enzymes, which may be further inhibited directly by high $\mathrm{PCO}_{2}$ concentrations. Overall, the positive effects of high target levels such as less bronchoalveolar damage may be abrogated by the negative effects. This corresponds to the results of the TA measurements.

\section{REFERENCES}

1. Monin P, Vert P. The management of bronchopulmonary dysplasia. Clin Perinatol (1987) 14(3):531-49.

2. Nickerson BG. Bronchopulmonary dysplasia. Chronic pulmonary disease following neonatal respiratory failure. Chest (1985) 87(4):528-35.

3. Horst PS. Bronchiolitis. Am Fam Physician (1994) 49(6):1449-53.

4. Katz R, McWilliams B. Bronchopulmonary dysplasia in the pediatric intensive care unit. Crit Care Clin (1988) 4(4):755-87.

5. Meissner HC. Economic impact of viral respiratory disease in children. J Pediatr (1994) 124(5 Pt 2):S17-21. doi:10.1016/S0022-3476(94)70186-5

6. Hakulinen AL, Jarvenpaa AL, Turpeinen M, Sovijarvi A. Diffusing capacity of the lung in school-aged children born very preterm, with and without bronchopulmonary dysplasia. Pediatr Pulmonol (1996) 21(6):353-60. doi:10.1002/ (SICI)1099-0496(199606)21:6<353::AID-PPUL2>3.0.CO;2-M

7. Koumbourlis AC, Motoyama EK, Mutich RL, Mallory GB, WalczakSA, Fertal K. Longitudinal follow-up of lung function from childhood to adolescence in prematurely born patients with neonatal chronic lung disease. Pediatr Pulmonol (1996) 21(1):28-34. doi:10.1002/(SICI)1099-0496(199601)21:1<28:: AID-PPUL5>3.0.CO;2-M

8. Bjorklund LJ, Ingimarsson J, Curstedt T, John J, Robertson B, Werner O, et al. Manual ventilation with a few large breaths at birth compromises the therapeutic effect of subsequent surfactant replacement in immature lambs. Pediatr Res (1997) 42(3):348-55. doi:10.1203/00006450-19970900000016

9. Dreyfuss D, Saumon G. Ventilator-induced lung injury: lessons from experimental studies. Am J Respir Crit Care Med (1998) 157(1):294-323. doi:10.1164/ajrccm.157.1.9604014

10. Kavanagh BP, Meyer LJ. Normalizing physiological variables in acute illness: five reasons for caution. Intensive Care Med (2005) 31(9):1161-7. doi:10.1007/ s00134-005-2729-7

\section{ETHICS STATEMENT}

This study was carried out in accordance with the recommendations of the International Conference of Harmonization Good Clinical Practice Guidelines and the protocol approved by the institutional review board of the university of Ulm medical faculty. All subjects gave written informed consent in accordance with the Declaration of Helsinki.

\section{AUTHOR CONTRIBUTIONS}

SG: substantial contribution to acquisition of data, analysis and interpretation of data, as well as drafting the article and giving final approval to be submitted. ML: participated in revising the article critically for important intellectual content and has given final approval of the version to be submitted. UU, YY, and SU: substantial contribution to analysis of tracheal aspirates. HF and HH: made substantial contribution to conception and design of the trial. JD: substantial contribution to statistical analysis of data. UT: substantial contribution to acquisition of data, analysis and interpretation of data, as well as revising the article critically for important intellectual content and giving final approval to be submitted.

\section{ACKNOWLEDGMENTS}

The authors wish to thank Nadine Ruske for excellent technical assistance. Furthermore, we thank the staff of the Ulm NICU for collecting and centrifuging samples. Last but not least, we thank all infants and their parents for participating. Grant number DFG: Th626/5-1.

11. Garland JS, Buck RK, Allred EN, Leviton A. Hypocarbia before surfactant therapy appears to increase bronchopulmonary dysplasia risk in infants with respiratory distress syndrome. JAMA Pediatr (1995) 149(6):617-22.

12. Kraybill EN, Runyan DK, Bose CL, Khan JH. Risk factors for chronic lung disease in infants with birth weights of 751 to 1000 grams. J Pediatr (1989) 115(1):115-20. doi:10.1016/S0022-3476(89)80345-2

13. Subramanian S, El-Mohandes A, Dhanireddy R, Koch MA. Association of bronchopulmonary dysplasia and hypercarbia in ventilated infants with birth weights of 500-1,499 g. Matern Child Health J (2011) 15(Suppl 1):S17-26. doi:10.1007/s10995-011-0863-0

14. van Marter LJ, Allred EN, Pagano M, Sanocka U, Parad R, Moore M, et al. Do clinical markers of barotrauma and oxygen toxicity explain interhospital variation in rates of chronic lung disease? The Neonatology Committee for the Developmental Network. Pediatrics (2000) 105(6):1194-201. doi:10.1542/ peds.105.6.1194

15. Carlo WA, Stark AR, Wright LL, Tyson JE, Papile L-A, Shankaran S, et al. Minimal ventilation to prevent bronchopulmonary dysplasia in extremelylow-birth-weight infants. J Pediatr (2002) 141(3):370-4. doi:10.1067/ mpd.2002.127507

16. Mariani G, Cifuentes J, Carlo WA. Randomized trial of permissive hypercapnia in preterm infants. Pediatrics (1999) 104(5 Pt 1):1082-8. doi:10.1542/ peds.104.5.1082

17. Thome UH, Carroll W, Wu T-J, Johnson RB, Roane C, Young D, et al. Outcome of extremely preterm infants randomized at birth to different $\mathrm{PaCO}_{2}$ targets during the first seven days of life. Biol Neonate (2006) 90(4):218-25. doi:10.1159/000092723

18. Finkelstein JN, Horowitz S, Sinkin RA, Ryan RM. Cellular and molecular responses to lung injury in relation to induction of tissue repair and fibrosis. Clin Perinatol (1992) 19(3):603-20.

19. Zimmerman JJ, Farrell PM. Advances and issues in bronchopulmonary dysplasia. Curr Probl Pediatr (1994) 24(5):159-70. doi:10.1016/0045-9380(94)90033-7 
20. Zimmerman JJ. Bronchoalveolar inflammatory pathophysiology of bronchopulmonary dysplasia. Clin Perinatol (1995) 22(2):429-56.

21. Groneck P, Speer CP. Inflammatory mediators and bronchopulmonary dysplasia. Arch Dis Child Fetal Neonatal Ed (1995) 73(1):F1-3. doi:10.1136/ fn.73.1.F1

22. Kotecha S. Cytokines in chronic lung disease of prematurity. Eur J Pediatr (1996) 155(Suppl 2):S14-7. doi:10.1007/BF01958074

23. Bagchi A, Viscardi RM, Taciak V, Ensor JE, McCrea KA, Hasday JD. Increased activity of interleukin-6 but not tumor necrosis factor-alpha in lung lavage of premature infants is associated with the development of bronchopulmonary dysplasia. Pediatr Res (1994) 36(2):244-52. doi:10.1203/ 00006450-199408000-00017

24. Groneck P, Gotze-Speer B, Oppermann M, Eiffert H, Speer CP. Association of pulmonary inflammation and increased microvascular permeability during the development of bronchopulmonary dysplasia: a sequential analysis of inflammatory mediators in respiratory fluids of high-risk preterm neonates. Pediatrics (1994) 93(5):712-8.

25. Kotecha S, Chan B, Azam N, Silverman M, Shaw RJ. Increase in interleukin-8 and soluble intercellular adhesion molecule-1 in bronchoalveolar lavage fluid from premature infants who develop chronic lung disease. Arch Dis Child Fetal Neonatal Ed (1995) 72(2):F90-6. doi:10.1136/fn.72.2.F90

26. Little S, Dean T, Bevin S, Hall M, Ashton M, Church M, et al. Role of elevated plasma soluble ICAM-1 and bronchial lavage fluid IL-8 levels as markers of chronic lung disease in premature infants. Thorax (1995) 50(10):1073-9. doi:10.1136/thx.50.10.1073

27. Murch SH, Costeloe K, Klein NJ, MacDonald TT. Early production of macrophage inflammatory protein-1 alpha occurs in respiratory distress syndrome and is associated with poor outcome. Pediatr Res (1996) 40(3):490-7. doi:10.1203/00006450-199609000-00020

28. Kotecha S, Wangoo A, Silverman M, Shaw RJ. Increase in the concentration of transforming growth factor beta-1 in bronchoalveolar lavage fluid before development of chronic lung disease of prematurity. J Pediatr (1996) 128(4):464-9. doi:10.1016/S0022-3476(96)70355-4

29. Kotecha S, Wilson L, Wangoo A, Silverman M, Shaw RJ. Increase in interleukin (IL)-1 beta and IL-6 in bronchoalveolar lavage fluid obtained from infants with chronic lung disease of prematurity. Pediatr Res (1996) 40(2):250-6. doi:10.1203/00006450-199608000-00010

30. Thome U, Kossel H, Lipowsky G, Porz F, Furste HO, Genzel-Boroviczeny O, et al. Randomized comparison of high-frequency ventilation with high-rate intermittent positive pressure ventilation in preterm infants with respiratory failure. J Pediatr (1999) 135(1):39-46. doi:10.1016/S0022-3476(99)70325-2

31. Mercier JC, Hummler H, Durrmexer X, Sanchez-Luna M, Carnielli V, Field D, et al. Inhaled nitric oxide for prevention of bronchopulmonary dysplasia in premature babies (EUNO): a randomize controlled trial. Lancet (2010) 376(9738):346-54. doi:10.1016/S0140-6736(10)60664-2

32. Thome U, Gotze-Speer B, Speer CP, Pohlandt F. Comparison of pulmonary inflammatory mediators in preterm infants treated with intermittent positive pressure ventilation or high frequency oscillatory ventilation. Pediatr Res (1998) 44(3):330-7. doi:10.1203/00006450-199809000-00011

33. Laube M, Amann E, Uhlig U, Yang Y, Fuchs HW, Zemlin M, et al. Inflammatory mediators in tracheal aspirates of preterm infants participating in a randomized trial of inhaled nitric oxide. PLoS One (2017) 12(1):e0169352. doi:10.1371/journal.pone. 0169352

34. Rauvala H, Hallman M. Glycolipid accumulation in bronchoalveolar space in adult respiratory distress syndrome. J Lipid Res (1984) 25(11):1257-62.

35. Chan C, Goldkorn T. Ceramide path in human lung cell death. Am J Respir Cell Mol Biol (2000) 22(4):460-8. doi:10.1165/ajrcmb.22.4.3376

36. Lavrentiadou SN, Chan C, Kawcak T, Ravid T, Tsaba A, van der Vliet A, et al. Ceramide-mediated apoptosis in lung epithelial cells is regulated by glutathione. Am J Respir Cell Mol Biol (2001) 25(6):676-84. doi:10.1165/ ajrcmb.25.6.4321

37. Uhlig S, Yang Y. Sphingolipids in acute lung injury. Handb Exp Pharmacol (2013) 216:227-46. doi:10.1007/978-3-7091-1511-4_11

38. von Bismarck P, Wistädt C-FG, Klemm K, Winoto-Morbach S, Uhlig U, Schütze $S$, et al. Improved pulmonary function by acid sphingomyelinase inhibition in a newborn piglet lavage model. Am J Respir Crit Care Med (2008) 177(11):1233-41. doi:10.1164/rccm.200705-752OC

39. Kunzmann S, Collins JJ, Yang Y, Uhlig S, Kallapur SG, Speer CP, et al. Antenatal inflammation reduces expression of caveolin-1 and influences multiple signaling pathways in preterm fetal lungs. Am J Respir Cell Mol Biol (2011) 45(5):969-76. doi:10.1165/rcmb.2010-0519OC

40. Sittipunt C, Steinberg KP, Rusinski JT, Myles C, Zhu S, Goodman RB, et al. Nitric oxide and nitrotyrosine in the lungs of patient with acute respiratory distress syndrome. Am J Respir Crit Care Med (2001) 163:503-10. doi:10.1164/ ajrccm.163.2.2004187

41. Zhu S, Manuel M, Tanaka S, Choe N, Kagan E, Matalon S. Contribution of reactive oxygen and nitrogen species to particulate-induced lung injury. Environ Health Perspect (1998) 106:1157-63. doi:10.2307/3433979

42. Thome UH, Genzel-Boroviczeny O, Bohnhorst B, Schmid M, Fuchs H, Rohde $\mathrm{O}$, et al. Permissive hypercapnia in extremely low birthweight infants (PHELBI): a randomised controlled multicentre trial. Lancet Respir Med (2015) 3(7):534-43. doi:10.1016/S2213-2600(15)00204-0

43. Wrigge $\mathrm{H}$, Uhlig U, Zinserling J, Behrends-Callsen E, Ottersbach G, Fischer M, et al. The effects of different ventilatory settings on pulmonary and systemic inflammatory responses during major surgery. Anesth Analg (2004) 98(3):775-81. doi:10.1213/01.ANE.0000100663.11852.BF

44. Goggel R, Winoto-Morbach S, Vielhaber G, Imai Y, Lindner K, Brade L, et al. PAF-mediated pulmonary edema: a new role for acid sphingomyelinase and ceramide. Nat Med (2004) 10(2):155-60. doi:10.1038/nm977

45. de Blic J, Midulla F, Barbato A, Clement A, Dab I, Eber E, et al. Bronchoalveolar lavage in children. ERS Task Force on bronchoalveolar lavage in children. European Respiratory Society. Eur Respir J (2000) 15(1):217-31.

46. Haslam PL, Baughman RP. Report of ERS Task Force: guidelines for measurement of acellular components and standardization of BAL. Eur Respir J (1999) 14(2):245-8. doi:10.1034/j.1399-3003.1999.14b01.x

47. Walsh MC, Wilson-Costello D, Zadell A, Newman N, Fanaroff A. Safety, reliability, and validity of a physiologic definition of bronchopulmonary dysplasia. J Perinatol (2003) 23:451-6. doi:10.1038/sj.jp.7210963

48. Groneck P, Reuss D, Gotze-Speer B, Speer CP. Effects of dexamethasone on chemotactic activity and inflammatory mediators in tracheobronchial aspirates of preterm infants at risk for chronic lung disease. J Pediatr (1993) 122(6):938-44. doi:10.1016/S0022-3476(09)90024-5

49. Groneck P, Goetze-Speer B, Speer CP. Inflammatory bronchopulmonary response of preterm infants with microbial colonisation of the airways at birth. Arch Dis Child Fetal Neonatal Ed (1996) 74(1):F51-5. doi:10.1136/fn.74.1.F51

50. Jonsson B, Tullus K, Brauner A, Lu Y, Noack G. Early increase of TNF alpha and IL-6 in tracheobronchial aspirate fluid indicator of subsequent chronic lung disease in preterm infants. Arch Dis Child Fetal Neonatal Ed (1997) 77(3):F198-201. doi:10.1136/fn.77.3.F198

51. Speer CP. Inflammatory mechanisms in neonatal chronic lung disease. Eur J Pediatr (1999) 158(Suppl 1):S18-22. doi:10.1007/PL00014314

52. Speer CP. Chorioamnionitis, postnatal factors and proinflammatory response in the pathogenetic sequence of bronchopulmonary dysplasia. Neonatology (2009) 95(4):353-61. doi:10.1159/000209301

53. Wagener BM, Roux J, Carles M, Pittet J-F. Synergistic inhibition of beta2-adrenergic receptor-mediated alveolar epithelial fluid transport by interleukin-8 and transforming growth factor-beta. Anesthesiology (2015) 122(5):1084-92. doi:10.1097/ALN.0000000000000595

54. Vicencio AG, Lee CG, Cho SJ, Eickelberg O, Chuu Y, Haddad GG, et al. Conditional overexpression of bioactive transforming growth factor-betal in neonatal mouse lung: a new model for bronchopulmonary dysplasia? Am J Respir Cell Mol Biol (2004) 31(6):650-6. doi:10.1165/rcmb.2004-0092OC

55. Ryu J, Heldt GP, Nguyen M, Gavrialov O, Haddad GG. Chronic hypercapnia alters lung matrix composition in mouse pups. JAppl Physiol (2010) 109(1):203-10. doi:10.1152/japplphysiol.00610.2009

56. Goggel R, Hoffman S, Nusing R, Narumiya S, Uhlig S. Platelet-activating factor-induced pulmonary edema is partly mediated by prostaglandin $\mathrm{E}(2)$, E-prostanoid 3-receptors, and potassium channels. Am J Respir Crit Care Med (2002) 166(5):657-62. doi:10.1164/rccm.200111-071OC

57. Hirabayashi A, Nishiwaki K, Taki K, Shimada Y, Ishikawa N. Effects of neuropeptide $\mathrm{Y}$ on lung vascular permeability in the pulmonary circulation of rats. Eur J Pharmacol (1994) 256(2):227-30. doi:10.1016/0014-2999 (94)90251-8

58. Kishimoto T. The biology of interleukin-6. Blood (1989) 74(1):1-10.

59. Nardelli LM, Rzezinski A, Silva JD, Maron-Gutierrez T, Ornellas DS, Henriques I, et al. Effects of acute hypercapnia with and without acidosis on lung inflammation and apoptosis in experimental acute lung injury. Respir Physiol Neurobiol (2015) 205:1-6. doi:10.1016/j.resp.2014.09.007 
60. Ranieri VM, Suter PM, Tortorella C, de Tullio R, Dayer JM, Brienza A, et al. Effect of mechanical ventilation on inflammatory mediators in patients with acute respiratory distress syndrome. JAMA (1999) 282(1):54. doi:10.1001/ jama.282.1.54

61. Curley G, Laffey JG, Kavanagh BP. Bench-to-bedside review: carbon dioxide. Crit Care (2010) 14(2):220. doi:10.1186/cc8926

62. Masood A, Yi M, Lau M, Belcastro R, Shek S, Pan J, et al. Therapeutic effects of hypercapnia on chronic lung injury and vascular remodeling in neonatal rats. Am J Physiol Lung Cell Mol Physiol (2009) 297(5):L920-30. doi:10.1152/ ajplung.00139.2009

63. Pfeiffer B, Hachenberg T, Wendt M, Marshall B. Mechanical ventilation with permissive hypercapnia increases intrapulmonary shunt in septic and nonseptic patients with acute respiratory distress syndrome. Crit Care Med (2002) 30(2):285-9. doi:10.1097/00003246-200202000-00003

64. Vertrees RA, Nason R, Hold MD, Leeth AM, Schmalstieg FC, Boor PJ, et al. Smoke/burn injury-induced respiratory failure elicits apoptosis in ovine lungs and cultured lung cells, ameliorated with arteriovenous $\mathrm{CO}_{2}$ removal. Chest (2004) 125(4):1472-82. doi:10.1378/chest.125.4.1472

65. Lang JD, Figueroa M, Sanders KD, Aslan M, Liu Y, Chumley P, et al. Hypercapnia via reduced rate and tidal volume contributes to lipopolysaccharide-induced lung injury. Am J Respir Crit Care Med (2005) 171(2):147-57. doi:10.1164/rccm.200302-305OC

66. Lang JD, Chumley P, Eiserich JP, Estevez A, Bamberg T, Adhami A, et al. Hypercapnia induces injury to alveolar epithelial cells via a nitric oxide-dependent pathway. Am J Physiol Lung Cell Mol Physiol (2000) 279(5):L994-1002.

67. Doerr CH, Gajic O, Berrios JC, Caples S, Abdel M, Lymp JF, et al. Hypercapnic acidosis impairs plasma membrane wound resealing in ventilator-injured lungs. Am J Respir Crit Care Med (2005) 171(12):1371-7. doi:10.1164/ rccm.200309-1223OC
68. O'Toole D, Hassett P, Contreras M, Higgins BD, McKeown STW, McAuley DF, et al. Hypercapnic acidosis attenuates pulmonary epithelial wound repair by an NF-kappaB dependent mechanism. Thorax (2009) 64(11):976-82. doi:10.1136/thx.2008.110304

69. Briva A, Vadász I, Lecuona E, Welch LC, Chen J, Dada LA, et al. High $\mathrm{CO}_{2}$ levels impair alveolar epithelial function independently of $\mathrm{pH}$. PLoS One (2007) 2(11):e1238. doi:10.1371/journal.pone.0001238

70. Donnelly SC, Strieter RM, Kunkel SL, Walz A, Robertson CR, Carter DC, et al. Interleukin- 8 and development of adult respiratory distress syndrome in at-risk patient groups. Lancet (1993) 341(8846):643-7. doi:10.1016/ 0140-6736(93)90416-E

71. Groneck P, Oppermann M, Speer CP. Levels of complement anaphylatoxin C5a in pulmonary effluent fluid of infants at risk for chronic lung disease and effects of dexamethasone treatment. Pediatr Res (1993) 34(5):586-90. doi:10.1203/00006450-199311000-00006

Conflict of Interest Statement: The authors declare that the research was conducted in the absence of any commercial or financial relationships that could be construed as a potential conflict of interest.

Copyright (c) 2017 Gentner, Laube, Uhlig, Yang, Fuchs, Dreyhaupt, Hummler, Uhlig and Thome. This is an open-access article distributed under the terms of the Creative Commons Attribution License (CC BY). The use, distribution or reproduction in other forums is permitted, provided the original author(s) or licensor are credited and that the original publication in this journal is cited, in accordance with accepted academic practice. No use, distribution or reproduction is permitted which does not comply with these terms. 